\title{
Knowledge Sharing, Organizational Capabilities, and Innovation Management to Sustain Competitive Advantage: A Qualitative Multi-Case Study
}

\author{
Ghayth Tahat \\ School of Business and Technology, Capella University \\ Georgia, USA \\ Tel: 1-843-327-4752_E-mail: Engtahat@hotmail.com
}

Received: Nov. 13, 2020 Accepted: Jan. 10, $2021 \quad$ Published: January 10, 2021

doi:10.5296/jmr.v13i1.18147ＵRL: https://doi.org/10.5296/jmr.v13i1.18147

\begin{abstract}
The importance of new product development (NPD) and innovative capabilities in marketing, innovation, and business strategy has been recognized by management and researchers. Knowledge management and organizational capabilities are also explored and evaluated by researchers and practitioners. However, the current literature shows a lack of connection between NPD, innovative capabilities, integrated shared knowledge, and organizational capabilities. Also, there is limited knowledge on the impact and the contribution of the integrated shared knowledge and the organizational capabilities to the firm's success, performance, and sustainability. This study aims to determine if there is a link between NPD and innovative capabilities and the integrated shared knowledge and the organization's capability and explore how shared knowledge and the organization's capabilities influence and contribute to NPD, innovative capabilities, and innovative management. A qualitative, multi-site case study through one-on-one, in-depth interviews with primary decision-makers from technology and innovative companies in Jordan is employed. The primary research question is, how do shared knowledge and the organizational capabilities that influence NPD and innovative capability contribute to the firm's success, performance, and sustainability? Respondent interviews are imported and analyzed through NVivo qualitative data analytics software. Findings are also determined using NVivo 11 through theme analysis. A key finding is that shared knowledge and the organization's capabilities are linked and critical for NPD's success and innovative capabilities.
\end{abstract}

Keywords: Knowledge sharing, organization capabilities, innovation management, and competitive advantage. 


\section{Introduction}

The importance of new product development decisions in business strategy has been recognized by strategy researchers and business leaders (Lin \& Chen, 2008). There is a substantial amount of research regarding NPD and innovative capability and its effects on the firm's sustainable competitive advantage (Ernst, 2002; Zhang, 2012). Existing literature ignores the role and the impact of shared knowledge and the organization's capabilities on NPD and innovative capabilities and their contribution to the firm's success, performance, and sustainability (Lin \& Chen, 2008). Current literature fails to address the influence of shared knowledge and the organization's capabilities on managerial innovation-decision and strategic planning related to NPD and innovative capabilities (Kahn, Barczak, \& Moss, 2006, 2012; Vinayak \& Kodali, 2014). To determine the role of shared knowledge and the organization's capabilities on NPD and innovative capabilities, the researcher has conducted a multi-site case study that involved interviewing primary decision-makers from technology and innovative companies in Jordan.

Innovation is the lifeblood of firms that compete in dynamic environments (Slater, Mohr, \& Sengupta, 2014). Innovation has a profound influence on organizational performance, survivability, and several strategic advantages such as eliminating cost, reducing risk, differentiation in new products or services, and increasing quality (Yeşil, Koska, \& Büyükbeşe, 2013). Lawson and Samson (2001) stated that "innovation is a firm's source of new products, processes, and systems for adapting to a changing market" (p. 381). Innovation has been a determinant of survival for any organization; consequently, continuous innovation is instrumental in sustaining competitive advantage in dynamic markets ( $\mathrm{Xu}$, Houssin, Caillaud, \& Gardoni, 2010). Innovation is the driving force behind introducing new products, processes, or markets that spawn modern economies and generate new wealth $(\mathrm{Xu}$ et al., 2010). Smithies (n.d.) stated in addressing the relation between economics with innovation, which agrees with Schumpeter's (2002) interpretation of economics and innovation, believed the success of the business performance and value creation depends on an organization's robust innovation process. The advancement of technology and communication and the increasing level of global competition caused industries and manufacturers to emphasize innovation and the development of new products (Xu et al., 2010).

Innovation is a primary method that ensures sustainable competitive and corporate economic viability (Moustaghfir \& Schiuma, 2013). Developing new products or improving existing products by adding new values is the spirit of innovation and manufacturing companies (Moustaghfir \& Schiuma, 2013). Innovation enables companies to gain a competitive advantage and sustain the core competence and market share of the firm (Moustaghfir \& Schiuma, 2013). A part of that competitive advantage is derived from the effective use of innovative ideas through new product development (NPD) and the implementation of innovation.

Organizations recognize and are aware of the essential factors and the critical role of innovation to growth, competitiveness, and the contribution of NPD in developing and 
sustaining the core competencies for long-term competitive advantage and success (Liu, Wang, Yuan, \& Li, 2012). Yang and Yu (2012) stated that the "NPD process can be viewed as a series of activities, including idea generation, product development, and product commercialization" (p. 220). Ngamkroeckjoti, Speece, and Dimmitt (2005) provided a basic definition for NPD as "a process of creating and launching products. From identifying the business needs to its commercialization" (p. 29).

Companies can fulfill new customer needs, capture new markets, and extend their prominence in a competitive environment through developing new products or enhancing the existing products (Cheung, 2015). Innovation is recognized as an engine for economic growth (Singh \& Bhangoo, 2014) and is cited as an essential valuable element for sustaining competitive advantage (Malewicki \& Sivakumar, 2004). Innovation consistently contributes to NPD (Cooper \& Kleinschmidt, 2010) and is the foundation of new product development (Phillips, 2016).

\section{Problem of the Study}

Innovative and manufacturing companies are concerned with being more proactive and adaptive by developing new values, products, or services, and innovative capability at a faster rate to satisfy consumers' demands. NPD and innovative capabilities seek to achieve, maintain, and sustain competitive advantage (Liker \& Morgan, 2011) due to the new communications techniques, the advanced technologies, globalization and dealing with the organizations' challenges that include developing the competitiveness and the creation of competitive advantage (Badrinarayanan \& Arnett, 2014). NPD and innovative capabilities need to be continuously assessed and improved based on the consumers' demand and market needs.

The objective of innovation, particularly NPD, is to provide the manufacturing and innovative organization with the leverage or the advantage of market innovation that supports the business plan with minimum risk (Ismail \& Yusof, 2010). NPD's success is linked to the firm's innovative capability (Lawson \& Samson, 2001). Innovative capability consists of an organization's intangible property and the ability to exploit this property in such a way that the organization can produce innovations perpetually (Saunila \& Ukko, 2013). Lawson and Samson (2001) defined innovative capability as "the ability to continuously transform knowledge and ideas into new products, processes, and systems for the benefit of the firm and its stakeholders" (p. 389).

The extant literature indicates that NPD and innovative capability are central factors to the firm's performance, survival, economic growth, and competitive advantage (Ismail \& Yusof, 2010). Innovation and increased NPD capabilities have become a significant concern for all companies that seek growth and prosperity (Yang \& Yu, 2012). NPD and innovative capabilities help firms differentiate themselves (Zhang \& Zhu, 2015) and enhance their advantage (Yang \& Yu, 2012). The presence of NPD and innovative capability had become significant elements of advanced competitive strategies among manufacturing and innovative companies (Narkhede, 2017; Woschke, Haase, \& Lautenschläger, 2016). 


\section{Mll Macrothink}

Journal of Management Research

ISSN 1941-899X

2021, Vol. 13, No. 1

The critical role and the advantages of embracing NPD caused innovative and manufacturing organizations to consider NPD to be a part of the company's strategies and to maintain a competitive advantage (Vinayak \& Kodali, 2014). NPD is deemed an essential area in developing and contributing to the firm's competitive advantages (Alvarez \& Iske, 2015; Brunswicker \& Vanhaverbeke, 2014; Vinayak \& Kodali, 2014). NPD is also considered as an essential process to attain the firm's objectives, success, strategic planning, training development and sustain the competitive advantage, and organizational renewal in fast-paced or competitive markets (Kang \& Kim, 2010; Rai, 2011). Lin and Chen (2008) found in their research on the success factors of NPD and innovative capabilities that a firm's innovation capability is developed through two perspectives. The two perspectives appear to have stimulated managers and scholars to understand innovation capability and NPD. The two perspectives are the behavioral aspect of the innovative organization and the organization's willingness to adapt to the required changes (Hussein \& Mourad, 2014; Lin \& Chen, 2008).

NPD and innovation capability enable the organization to integrate and reconfigure competence toward achieving goals and addressing the changing environment (Anders, 2006; Dangol \& Kos, 2014; Teece, Pisano, \& Shuen, 1997, 2003). The importance of NPD and innovative capability has led scholars to investigate new product success that they understand better the factors essential for NPD and innovation capability (Awwad \& Akroush, 2016). In this regard, Barclay, Dann, and Holroyd (2000, p. 59) suggested that NPD is a "tailored process"; "a company's development environment is unique to that company," therefore, as NPD processes must be "tailored" to suit the specific circumstances. Successful NPD and the implementation of innovative capabilities are crucial for firms across the industries. However, the development of successful NPD and innovative capabilities remains difficult and challenging. Nearly 50\% of new products introduced each year fail (Awwad \& Akroush, 2016). The success or failure rates caused organizations to be adaptive, proactive, and improve processes and products (Awwad \& Akroush, 2016).

Researchers identified and discussed the various factors comprehensively, affecting and contributing to the success of NPD and innovation capability in any firm (Barclay et al., 2000; Lin \& Chen, 2008), which are consistent with Cooper's (2005), Cooper's, Edgett's, and Kleinschmidt's (2007), Cooper's and Schindler's (2008) model, and Yodhia's (2010) factors. The common factors in NPD success across highly productive and best performers in NPD are revealed in the American Productivity and Quality Centre (APQC) study. Those common success factors of NPD are product innovation, technology strategy, resource commitment, effective and flexible implementation system, and the right climate for innovation, true cross-functional- teams, and management commitment (Ismail et al., 2012). Accordingly, the problem of the study lies in exploring the impact of knowledge sharing, organizational capabilities, and innovation management to sustain competitive advantage in companies in Jordan.

\section{Rationale of the Study}

NPD and innovative capabilities for many firms are a potential source of competitive advantage in evolving markets (Li, Zheng, \& Wang, 2016). There is a substantial amount of 
research regarding factors that affect NPD and innovative capability and their effects on the firm's sustainable competitive advantage. Also, the relationship between NPD and innovation capability has been tested in the literature (Ernst, 2002; Kahn et al., 2012; Vinayak \& Kodali, 2014; Zhang, 2012). Even though researchers and practitioners contended to explore the success and the affecting factors of NPD and organizational capabilities, more insights are required to manifest the paradigm. Existing literature ignores the role and the impact of shared knowledge and the organization's capabilities on NPD and innovative capabilities and their contribution to the firm's success, performance, and sustainability. The existing literature fails to address the influence of shared knowledge and the organization's capabilities on managerial innovation-decision and strategic planning related to NPD and innovative capabilities. This multi-site case study explores how shared knowledge and the organization's capabilities contribute to the firm's success, performance, and sustainability and examines the connection and the critical role of shared knowledge and organizational capabilities that affect NPD and innovation capabilities. By answering the research questions, the study enhances the understanding of how shared knowledge and the organization's capabilities impact NPD, and innovative capabilities contribute to the firm's success, performance, and sustainability.

The findings may reveal new insights and perspectives relevant to understand how shared knowledge contributes to the success of NPD and innovative capability and the firm's performance and sustainability. The findings may also yield important managerial implications and assist in the decision-making process regarding the creation of sustainable competitive advantage. The identification of how shared knowledge and the organization's capabilities contribute to the firm's success, performance, and sustainability may help managers understand what makes a firm more efficient and well-organized in NPD and innovative capabilities activities and processes. The new insight is necessary for managers who aim to increase success, performance, and maintain the competitive advantage of the firm. The results may also contribute to the existing literature on NPD and innovative capabilities by diminishing the gap between theory and practice.

\section{Objective of the Study}

This current study aims to determine if there is a link between NPD and innovative capabilities and the integrated shared knowledge and the organization's capability and explore how shared knowledge and the organization's capabilities influence and contribute to NPD, innovative capabilities, and innovative management.

\section{Questions of the Study}

This study has a central question and three sub-questions as follows:

1. How do shared knowledge and the organization's capabilities affecting NPD and innovative capability contribute to its success, performance, and sustainability?

Sub-questions are also needed to support the fundamental questions. The sub-questions are: 
1. What is the importance of shared knowledge and the organization's capabilities regarding their effect on product innovations and the firm's performance?

2. What are the benefits of shared knowledge and the organization's capabilities to the firm's success and performance?

3. How do shared knowledge and the organization's capabilities contribute to the organization's strategic planning and objectives?

\section{Significance of the Study}

This multi-site case study is significant to innovation management by providing organizations with a better understanding of the factors deemed critical to the success of NPD and innovative capability, which aid organizations with strategic planning and decision-making pertaining to NPD and innovation capability. Increasing awareness of these factors provides organizations with a foundation from which to explore their support or development of NPD and innovative capability that contribute to the firm's success, performance, and sustainability.

The findings may assist innovative management, practitioners, academics, and researchers in answering, developing, or identifying questions related to research purposes. The findings may also help develop a comprehensive understanding of the contribution and impact of the integrated shared knowledge and the organizational capabilities to the firm's success, performance, and sustainability, assisting the firm in developing new practices, programs, and decisions and better strategic plans.

\section{Previous Studies}

Despite the identification of the success factors contributing to the success of NPD and innovative capabilities implementation, innovative and manufacturing organizations still encounter a high rate of failure (Zaidi \& Othman, 2014). The failure causes have been summarized by the low execution quality and lack of focus and communications (Kleinschmidt, 1991; Lin \& Chen, 2008;). With that, researchers and practitioners are exploring other factors that impact the success of NPD and the innovative capability implementation to sustain existing competitive advantage, attain the strategic plans, achieve the firm's goals, and have better performance and productivity (Lin \& Chen, 2008).

Innovative and manufacturing organizations need to be proactive and rapidly active to respond to the dynamic environment and the changes in the consumers' trends. Time and the scarcity of resources are the main obstacles to attain those features, where companies acquire knowledge from outside sources that are useful based on the firm's organizational capability (Eisenhardt \& Martin, 2000). Lin and Chen (2008) recommended investigating the relationship between knowledge management and the integration of shared knowledge of customers, suppliers, and internal capabilities and new product development to examine the impact of applying and exploiting the acquired knowledge from external resources. The recommendations are based on exploring other factors that impact the success of NPD and the innovative capability implementation to sustain existing competitive advantage, achieve 
the firm's goals, and have better performance and productivity (Lin \& Chen, 2008). Another recommendation is to explore the role of shared knowledge and organizational capabilities on the firm's success, performance, and sustainability, and examine how shared knowledge and organizational capabilities contribute to NPD, innovative capability, and innovative management.

Innovative firms are aware of the essential role of shared knowledge in developing and sustaining a competitive advantage (Lin \& Chen, 2008). Firms apply a shared knowledge base as a resource capability that facilitates the collaboration and cooperation between the entire members and departments (Lin \& Chen, 2008). Hong, Doll, Nahm, and Li (2004) addressed three types of knowledge sharing that firms must consider, utilize, and implement in their strategic and training planning. The three types of knowledge sharing, according to Hong, Doll, Nahm, and Li (2004), that regarded as the foundation of knowledge sharing are "shared knowledge of internal capabilities, shared knowledge of customers, and shared knowledge of suppliers (p. 105)." However, the role of the types of shared knowledge have never been addressed in innovative practice and product development (Lin \& Chen, 2008).

There is limited knowledge on the impact and the contribution of the integrated shared knowledge and the organizational capabilities to the firm's success, performance, and sustainability. The extant gap is how the integrated shared knowledge and the organization's capabilities contribute, link, and impact the firm's success, performance, and sustainability (Lin \& Chen, 2008; Vinayak \& Kodali, 2014). The current literature did not address the role and the impact of shared knowledge and the organization's capabilities on NPD and innovation capabilities and their contribution to the firm's success, performance, and sustainability (Yang \& Yu, 2012). The existing literature failed to address the influence of shared knowledge and the organization's capabilities on managerial innovation-decision and strategic planning that are related to NPD and innovative capabilities. Also, the role of shared knowledge that affects NPD and the firm's innovative capabilities had never been examined (Lilleoere \& Hansen, 2011), nor had it been linked to achieve the firm's success, performance and sustain the competitive advantage (Zhang \& Zhu, 2015). There is also information relevant to NPD and innovative capability that would benefit from further research (Brunswicker \& Vanhaverbeke, 2014; Kalluri \& Kodali, 2014).

There is also a gap in how shared knowledge and the organization's capabilities contribute to the firm's success, performance, and sustainability (Ismail et al., 2012; Lin \& Chen, 2008). There is limited knowledge of the role of how the integrated shared knowledge and the organizational capability contributing to the organization's strategic planning and objectives (Lin \& Chen, 2008). Also, the existing literature has not addressed the role of shared knowledge, and the organizational capabilities impact the role of NPD and innovation capabilities. The gap is discussed by many researchers who determined the factors affecting and impacting NPD and innovative capabilities (Ismail et al., 2012; Lin \& Chen, 2008, 2008). As a result, further investigation is needed to explore how shared knowledge and the organization's capabilities affect NPD and innovative capabilities regarding their contribution to the firm's success, performance, and sustainability. The purpose of the study is to examine how the integrated shared knowledge and organizational capabilities impact on NPD and 
innovative capabilities, contribute to the firms' success and whether they lead to competitive product advantage.

This research addressed the gaps above by exploring how integrated shared knowledge and the organization's capabilities influence managerial innovation-decision and strategic planning. The research explores how integrated shared knowledge and organizational capabilities contribute to the firm's success, performance, and sustainability. Also, it explores the connection between the integrated shared knowledge and the organization's capabilities and the firm's NPD and innovation capabilities. This study contributes by presenting the important role and the connection of integrated shared knowledge and the organization's capabilities to NPD and innovative capabilities. Also, this study addresses how shared knowledge and organizational affect management and the firm's goals and plans.

\section{Theoretical \& Conceptual Framework}

The essence of this multi-case study consists of a qualitative methodology with an embedded, multi-case study. The methodology in this multi-site case study guides the researcher to obtain the necessary data and knowledge that benefits the participants, the innovative organizations, business practitioners, and researchers as well. The researcher selects the methodology based on the problem or opportunity to investigate, the purpose of the study, the theory base, or the nature of the data (Roberts, 2010). This study adheres to the methodological rigor of qualitative, multi-site case study design from Yin (2014) and Cooper and Schindler (2014). The focus of this multi-site case study is to explore how the integrated shared knowledge and the organization's capabilities affect NPD and innovative capabilities regarding their contribution to the firm's success, performance, and sustainability. The theoretical foundation of this multi-site case study is guided by the following theories: knowledge management, innovation, new product development, the resource-based view of the firm, and organizational learning. An in-depth understanding of the data is required to support the theoretical framework of this multi-site case study. It is the researcher's responsibility to demonstrated what makes this multi-case study a credible and interesting research study that has potential theoretical value (Alvesson \& Karreman, 2011).

The importance of the research lies in the outcome, which may be used by academics, researchers, and practitioners to develop a comprehensive understanding of how shared knowledge and the organizational capabilities contribute to the firm's success, performance, and sustainability. The findings may link the integrated shared knowledge and organizational capabilities to NPD and innovative capabilities. The significance of the study is to fill a gap in the existing literature regarding the role and the contribution of the integrated shared knowledge and the organizational capabilities to the firm's success, performance, and sustainability. The research is undertaken to develop a thorough understanding of the role and the connection between the integrated shared knowledge and organizational capabilities and the success of NPD and innovative capabilities. Also, the results of this research provide a better understanding of the role and the impact of the integrated shared knowledge and the organizational capabilities to the firm's success, performance, sustainability, and innovative 
management strategic planning and goals. The theoretical framework of the study is an outcome of the following three theoretical gaps in the innovation literature.

Theoretical Reason 1. There is limited knowledge on the impact and the contribution of the integrated shared knowledge and the organizational capabilities to the firm's success, performance, and sustainability

Theoretical Reason 2. The current literature did not address the role and the impact of the integrated shared knowledge and the organization's capabilities on NPD and innovation capabilities and their contribution to the firm's success, performance, and sustainability.

Theoretical Reason 3. The existing literature failed to address the influence of shared knowledge and the organization's capabilities on managerial innovation-decision and strategic planning related to NPD and innovative capabilities. Also, the role of shared knowledge that affects NPD and the firm's innovative capabilities had never been examined.

\section{Terms of the Study}

\section{The study has the following main terms:}

Innovation: Wang and Ahmed (2004) defined innovation as developing new products/services, new production methods, a new market, a new source of supply, and new organizational forms. Innovation is also defined to include an introduction to new products, successful commercialization of new combinations based on the application of new materials and components, the introduction of new processes, the opening of new markets, or the introduction of new organizational forms (Tepic, Kemp, Omta, \& Fortuin, 2013).

Innovation Capability: According to Neely, Filippini, Forza, Vinelli, and Hii (2001), an organization's innovation capability can be simplified as the potential to develop innovation and innovative achievement.

Knowledge Management (KM): Knowledge management is a management function that allows knowledge sharing and provides easy access to knowledge, know-how, experience, and expertise (Mamun, Muhammad, \& Ismail, 2017).

New Product Development (NPD): Clark and Fujimoto (1991) defined NPD as a business strategy and a process to convert market opportunities, technology, and customer needs into technical and commercial solutions.

Organizational Capabilities: Organizational capability refers to the knowledge, skills, and related routines that constitute a firm's ability to create and deliver superior value to customers (Johansson, Keränen, Hinterhuber, Liozu, \& Andersson, 2015). An organization's capabilities refer to a firm's capacity to deploy and coordinate different resources, usually in combination, using organizational processes, which affect the desired end (Lin, 2007).

Shared Knowledge: Liou, Chih, Yuan, and Lin (2016) defined shared knowledge as an individual's behavior dispersing obtained knowledge and information to others within an organization. Cummings and Teng (2003) explained shared knowledge as a means by which an organization receives access to its own or another organization's knowledge. For this study, 
shared knowledge or integrated shared knowledge includes understanding customers, suppliers, internal capabilities, and processes in the cross-functional product development team.

\section{Limitations of the Study}

The limitations of this study are related to the participants and the researcher. The sampling frame for this study and the inclusion requirements for the population sample is a boundary limitation of this study. The researcher does not have control over which the various applications and implementation of NPD and organizational capabilities. The researcher's lack of experience conducting interviews is also a limitation of this study. The researcher's inexperience could have inadvertently introduced participants' bias if the researcher did not insert enough objectivity into the interview process itself.

\section{Methodology and Design of the Study}

The research design for this study is a qualitative multi-site case study. This multi-site case study aims to answer the research question and achieve its purpose by studying a small, qualified participant sample, allowing the researcher to understand the organizations through the focus on the participants' perspectives regarding this phenomenon (Stake, 2006). The case study method is appropriate for answering how and what questions, where the setting and context of the data collected should be considered to answer the research question (Yin, 2015) appropriately. According to Marshall and Rossman (2016), "one of the strengths of the case study approach is the methodological eclecticism; a variety of methods may be used" (p. 19).

An exploratory qualitative multi-site case study is selected as it is appropriate for this research, using a variety of data sources to gain in-depth knowledge and a better understanding of the phenomenon within its context. The selection of a qualitative multi-site case study is made based on the researchers' interest in reviewing individual cases (Hyett et al., 2014). The purpose of this multi-site case study is to examine how shared knowledge and the organization's capabilities contribute to the firm's success, performance, and sustainability. Also, this multi-site case study aims to explore the link between shared knowledge and organizational capabilities and NPD and innovation capabilities. The researcher in this multi-site case study focuses on the participants' perspectives and the subjective reviews that can only be obtained by a qualitative method. The study is structured on Eisenhardt's (1989) process of planning, selecting cases, applying overlapping data, shaping hypotheses through tabulation of evidence, comparing and constructing findings within the literature, and offering new conceptual frameworks when themes saturation has been reached. This structure allows an iterative approach to research planning, design, preparation, data collection, analysis, and reporting each case in detail.

Throughout the interview with the selected participants, the participants are asked to define NPD, innovation capability, and the leading factors that affect NPD and innovative capability, including offering a brief explanation of why each factor is selected. To develop a better understanding of their perceptions, they are asked to describe the role and the impact of shared knowledge and the organization's capabilities regarding the contribution to the firm's 
success, performance, and sustainability. Interview data are triangulated with each organization's quality, operations, innovative applications, innovation capabilities, objectives, vision, and other relevant documents such as strategic plans, annual reports, or internal communications.

\section{1 Target Population and Sample}

Qualitative researchers may categorize the respondent pool as the sample, but sampling technique definitions infer statistical analysis of a representing of the entire population in the universe (Yin, 2014). This multi-site case study design did not obtain respondents through sampling; and, it applied Yin's (2014) concept of analytic generalization, which contends that respondents are purposefully selected to shed empirical light on theoretical and principles.

This multi-site case study aimed to answer the research question and achieve its purpose through the study of a small, qualified participant sample, allowing the researcher to gain a stronger understanding of the organizations (Stake, 2006). The target population for this multi-site case study is experts, executive team members, business owners, and professionals of NPD and innovative organizations in the Jordan market recognized by the community based on several factors, including innovative performances, innovative practices, and innovative capabilities. The innovative companies, whose core business is directly related to NPD and the implementation of innovative capabilities recognized by the Jordanian community, are the sampling frame for this study.

\subsection{Population}

The target population for this multi-site case study is experts, executive team members, business owners, and professionals of NPD and innovative organizations in the Jordanian market. Inclusion requirements for the population sample include individuals who are currently employed and directly involved in innovation practices and NPD projects or studies. The participants must have obtained at least a bachelor's degree with at least seven (7) years with significant operational and administrative authority. The selected organizations varied in the size of operations, number of employees, field, and core competence.

\subsection{Sample}

The sample for this study consisted of executive team members and experts from each of the selected sites for this study. The recruitment sample size is 50 innovative organizations in the Jordanian market from various specializations. From the sample size of 50, the researcher is able to conduct 29 interviews representing 29 innovative Jordanian companies with qualified participants. Characteristics of the ideal sample included both the project manager expert/executive team member of new product development project teams that utilize NPD and innovation capabilities. The researcher is able to interview qualified participants to collect different perspectives and to conduct a deep and detailed study regarding this phenomenon. Purposive sampling selection is derived based on Patton (2015) and Yin (2014) recommendations, as Patton stated that "purposive sampling emphasizes an in-depth understanding and learning a great deal about the inquiry issue" (p.137), and Yin stated that 
"purposive sampling ensures that the participants will have the experience, information, and knowledge to answer the research question" (p. 87).

\subsection{Qualitative Data Collection}

A list of 50 companies is selected from the Jordanian market for this study, and another ten are selected as a backup. The researcher reached 29 innovative organizations and interviewed 29 qualified participants from those organizations. The number of selected organizations is based on the purpose and the intent of the study (Cleary et al., 2014). The appropriate sample for this study has resulted in sufficient saturation of the participants' interviews for the research (Eisenhardt \& Graebner, 2007; Stake, 2006). Stake (1995, 2006) recommended that researchers conducting a qualitative study should have a sample size that would enable the researcher to answer the research questions.

Contact information for the selected innovative organizations is obtained through the websites of each identified organization. The researcher contacted the identified site representative via phone to describe the study and sampling frame, to request contact information, and to ask for their organization's support and participation in this study to conduct research on-site. The researcher visited each organization's site after gaining approval and their support to participate. Then the researcher spoke with the gatekeeper of each organization in-person to provide more details pertaining to the study and to answer any questions or concerns. The researcher requested the contact information for the individuals that met the research's requirements and qualifications from the appropriate organization representative based on the inclusion criteria.

The primary collection method instrument for this study is the in-depth, intensive, semi-structured interview using open-ended questions. Interviews provided a well-organized method for gathering a great deal of detailed, empirical data, particularly in unique or complex scenarios (Eisenhardt \& Graebner, 2007; Patton, 2015). Each of the participants is interviewed individually based on a previously prepared list in a place that had private accommodations and is mutually acceptable to both the participant and the interviewer. A set of open-ended questions are designed to collect and obtain data to clarify and provide a better understanding of the topic or the phenomenon (Yin, 2014). Open-ended questions allowed respondents to answer in detail, clarify responses, and to get close and special attention to the interviewee's view and perspective about their experiences and their related meaning (Yin, 2014). Depending on the participants' answers, probing is used as needed to provide a deeper understanding of the shared perspective, issue, or topic. Probing questions are ideal for the researcher to clarify the respondent's perspective and assist the researcher in thinking critically and analytically.

This study acquired data from primary decision-makers of the most recognized innovative businesses and providers in Jordan based on Chamber of Commerce, as they are classified into small with less than 50 employees, medium with less than 150, and large with more than 250 employees. The researcher is only able to access and to interview only three (3) large innovative Jordanian organizations. A limitation is present in the collection of information from the primary decision-makers of the larger businesses. The researcher captured 
information about respondents about NPD and innovative capabilities roles, and the impact of shared knowledge and the organization's capabilities, with at least seven years of experience, and power that may influence business innovation or strategic agility or operations within the organization.

The participants are assured that all the information provided, their organization identity, and the personal perspectives' and views would remain confidential. Considering the lack of interaction between the researcher and participant in this type of interview, it becomes crucial for the researcher to build rapport with the participant (Trier-Bieniek, 2012). That is achieved by creating small talk before the interview began to better identify with one another (Trier-Bieniek, 2012). With all the assurance of confidentiality, two (2) out of the 29 participants refused to record the interview; they just allowed the researcher to take notes while conducting the interview and viewing the organization documents. Each interview is recorded by a voice recording device with a high level of filtration to reduce noise, miss-hearing, or interruption and to ensure that the interview is recorded clearly with high quality.

\subsection{Data Analysis}

The researcher's analysis includes direct quotations from the participant interviews. The quotations are used as the basis in support of the researcher's analysis. The qualifying data obtained through the interview is prepared and reviewed for eligibility by the researcher. This multi-site case study combined traditional and contemporary data analysis practices. Traditional techniques cannot entirely replicate features of qualitative data analysis software, and the traditional techniques must be applied before and after the use of the qualitative data analytics software (Yin, 2014). The combination of traditional and contemporary strategies delivered increased dependability, credibility, validity, and reliability.

Once the researcher completed the initial analysis, NVivo 11 is used to perform a similar type of analysis. NVivo is the suggested qualitative data analytics software for the multi-site case study, serving as the central software tool. The function of NVivo is to convert unstructured data to structured data through the process of coding. NVivo 11 is used to manage and analyze the data. NVivo 11 is utilized further to uncover themes, frequencies, and similarities. Furthermore, the results of both the researcher and NVivo 11 are then compared to build further upon the findings. Chapter 4 provides detailed information on both the researcher performed and NVivo 11 analysis.

\subsection{Instruments}

The obtained data through a one-on-one interview is recorded, transcribed, and analyzed by the researcher and by NVivo 11. The NVivo 11 program is used as the primary tool for organizing, managing, and analyzing the data. Bazeley and Jackson (2013) recommend using NVivo to guide the research's data collection and analysis. Literature, memos, and annotations are used to initiate the project in NVivo to create a foundation for organizing the data as it is collected and verifying conclusions drawn from the analysis. Interview 
transcriptions, organizational documents, and sources of evidence collected and considered are added to the NVivo project.

The data collected is transcribed prior to the use of NVivo 11. The researcher had to get absorbed and engaged with the data to understand the phenomena being explored and then developed a coding system to employ within the software (Noble \& Smith, 2014). The researcher's analysis is performed before the NVivo 11 analysis to validate any results that may surface from the software. By running the NVivo 11 analysis after the researcher has conducted the initial analysis, any possible bias is removed that may be encountered if the software analysis is run first.

Seers (2012) recommended reviewing the transcripts paragraph by paragraph to determine the coding process so as not to become overwhelmed with the data. Franzosi, Doyle, Mcclelland, Putnam Rankin, and Vicari (2013) recommended using code families to reduce the number of codes produced by NVivo 11 and to simplify the data. Generating word clouds from the platform elevated visualization of the data and are applied to increase readability. Coding plans began with the research questions and the interview questions, and the codes are not conclusive until after data collection (Swanson \& Holton, 2005). NVivo 11 is used further to uncover themes, frequencies, and similarities that the researcher is unable to determine. Furthermore, the results of both the researcher and NVivo 11 are then compared to build further upon the findings.

The findings produced in NVivo 11 are far more advanced than that of the researcher. There are many similarities in the overall determination that is made by the researcher. Anyan (2013) mentioned that a researcher has the power to interpret the data on how they best feel will answer the research question; therefore, using another form of analysis to support the findings of the researcher will contribute to the validity of the study. According to Jirwe (2011), NVivo 11 is also considered advantageous since it allows the researcher to identify consistency and inconsistency in their data analysis.

\section{Qualitative Research Findings}

It is determined that the integrated shared knowledge and the organization's capabilities have a critical effect and positive impact on the Jordanian innovative team members, the innovative managerial planning, and strategies, and contribute to the firms' success, performance, and sustainability. The study emphasizes the importance of the firm's use of shared knowledge and the organization's capabilities effectively by the NPD and team members. This multi-site case study focused on gathering information and data from qualified participants within the field on NPD and innovative capability in relation to the role of the shared knowledge and the organization's capabilities regarding their contribution to the firm's success, performance, and sustainability. It is discovered through this study that the integrated shared knowledge and the organization's capabilities are interconnected, and significantly affecting NPD and innovative capabilities, and contribute to the firm's success and performance. Also, other factors affecting the NPD and the innovative capabilities of an innovative firm that the participants shared are addressed as well. Project and innovative managers can now use one or more of these factors in support of more effective NPD and 
innovative practices. The research findings add value to managers and leaders, minimize the risk and the uncertainty, and also develop foresight for the changes and the practices that impact NPD and innovative capability as well. Consequently, the results of the exploratory multi-site case study can add new knowledge and principles to innovative management and competitive advantage theory through the increase in awareness and research of connecting and involving the role and the contribution of the integrated shared knowledge and the organization's capabilities to the firm's success, performance, and sustainability.

The results and the findings of this study are significant to the field of innovation management because it aims to provide a better understanding of the factors that impact the success of NPD and innovative capability and to consider new factors that are deemed essential for innovative firms. The findings can aid organizations with strategic planning and decision-making as it pertains to NPD and innovative capability and contributes to the firm's success, performance, and sustainability.

\section{Discussion and Results}

The determination by the researcher supports that participants felt that shared knowledge and the organization's capabilities are needed by the NPD teams towards success and achieving the firms' innovative objectives. Also, they expressed the essential, critical, and vital role of the shared knowledge and the organization's capabilities with innovative management not only to stay competitive but also to improve and enhance the product development process. Furthermore, in support of the central research question, the researcher is able to determine that shared knowledge and the organization's capabilities have an extreme connection to the firm's success, performance, competitiveness, and sustainability. Also, the researcher is also able to affirm that shared knowledge and organizational capabilities have a critical impact on the firm's success, performance, building, or improving the competitive advantage. This effect can be proven and seen in any innovative firm, especially for NPD team members.

NVivo 11 is utilized to validate and find any other meaning within the data. NVivo 11 found that the word frequencies of the five determined topics are in line with the researcher's hand-coding. The NVivo 11 analysis pointed out the impact and the contribution of the shared knowledge and the organization's capabilities and the effect on the innovative management strategic planning and practices. The identified themes affirmed a more positive attitude toward NPD and innovative capability after the shared knowledge and the organization's capabilities are implemented.

The researcher and the results from NVivo determine that shared knowledge and the organization's capabilities are significantly connected and supportive of the success of NPD and innovative capabilities. The results also determined that shared knowledge and the organization's capabilities contribute to the firm's success, performance, and sustainability. The contribution is seen by achieving the organization's objectives, sustaining the competitive advantage, and improving the firm's performance, which is also done by increasing and enhancing the NPD and the innovative capabilities rates and processes. 


\subsection{Conclusions Based on the Results}

This study began as an effort to understand better the role of shared knowledge and the organization's capabilities that impact NPD and innovative capability. Also, it is designed to explore how shared knowledge and the organization's capabilities contribute to the firm's success, performance, and sustainability. The researcher designed this study to focus on the participant's perspectives and opinions in the field of innovation and strategic management, particularly NPD and innovative capability, within manufacturing and innovative organizations that currently utilize shared knowledge and organizational capability.

The results by the researcher and the NVivo analysis show that shared knowledge and the organization's capabilities are significantly connected and supportive to the success of NPD and innovative capabilities and contribute to the firm's success, performance, and sustainability. The results also indicate that the team members of NPD shared knowledge enables the firm to improve or increase the innovative capabilities, new product competitive advantage and to add values to the products based on the market's and the consumers' desires. It is determined that there had been an improvement in the firm's performance and competitiveness when implementing shared knowledge and the organization's capabilities through the firm's innovative activities and practices. Individuals who have had experience with NPD and innovative capability affirmed that their perception and experience of shared knowledge and the organization's capabilities had been positive and critical to NPD and innovative management.

The results indicated that shared knowledge, as an extension to the knowledge in a firm, is an array of actions that assist and facilitate the team members to attain the desired project objectives and achieve the firm's goals. Shared knowledge offers many benefits not only to the firms by increasing and improving the firm's performance, sustaining the competitive advantage, and maintaining the market share but also to the team members by increasing the level of collaboration and cooperation through the entire organization. The benefits of shared knowledge integration include empowering the exchange of knowledge, facilitating learning, promoting the organization's strategies, and enhancing the competencies of the employees and the organization's capabilities to achieve individual and organization goals, assisting in reconfiguring the available resources, and maintaining competition in the market. Shared knowledge appears as a social process and contributes to the firm's success, performance, and sustaining a competitive advantage. It is proven based on the data analysis that the effectiveness of NPD and the innovative capabilities of the firm depends on the integration of information and knowledge within the organization and on a suitable combination of organizations' resources. Also, the results indicated that organizational competence essential for the NPD and innovative capabilities success are to be cognizant of what it knows and to have the ability to refigure the resources, recombine the knowledge and apply what it knows when it is needed to provide the firm the leverage to be more adaptive and proactive. More importantly, by taking advantage of knowledge sharing not only by utilizing sharing knowledge but also by exploiting the knowledge sharing, NPD and innovative capacity can improve the performance, increase the success rate, reduce the risk factors, and develop a superior product that aims to add value. When utilized in conjunction with the firm's 
organizational capabilities, shared knowledge is one of the best practices that have a significant impact on NPD and innovative capabilities success.

It is determined that for innovative firms to succeed in the implementation of NPD and innovation capabilities, firms require internal resources and capabilities to absorb, assimilate, and reconfigure externally obtained knowledge. Innovative companies must develop skills in coordinating the firm's resources and utilizing them in the most productive and efficient manner. The results affirmed that the company's capabilities are the product of its organizational structure, strategic planning, management support, processes, practices, and control, and monitoring systems.

Innovative firms need to develop and revamp "strategic flexibility" to ensure NPD and innovative capabilities success. Strategic flexibility as a strategic capability enables the firm to be more proactive and the ability to be rapid adaptive to the changes and the challenges in the global markets and business environments. The benefits of developing strategic flexibility include creating new skills, opportunities and delivering new products successfully through the effective utilization of the firm's resources and knowledge.

The findings show that organizational capabilities are another important NPD performance measure and contribution to sustaining the competitive advantage of the firm. Organizational capabilities build and integrate competencies across processes and activities, ultimately lead to product innovation, and maintain the competitive edge. Organizational capabilities seek to utilize the firm's resources effectively and increases organizational learning by building and sharing knowledge through the firm's processes and activities.

NPD is viewed by the researcher and from the data analysis as an ongoing process that requires integration and collaboration with all departments, not to mention, knowledge from various areas to achieve the firm's objectives and to ensure success. The results showed that having a knowledge base and being familiar with the organization capabilities of the firm enables innovation and NPD managers to identify which agile capabilities are needed and what best practices and strategies are essential to cope with the dynamic environment and provide the firms with the ability to become adaptive and proactive. NPD's success depends on the managers' ability to utilize the available resources and the knowledge in the processes of developing new products, developing the strategic planning and decision, and integrating the firm's capabilities in operations, which collectively contributes to the firms' performance and maintaining the competitive advantage.

The success of NPD and innovative capabilities range from embracing the concept of knowledge management and instilling the extension of knowledge management's notion and practices into the firm's structure, training, and processes, which provide the firm the leverage to sustain their competitive advantage and to maintain the market share. Developing a knowledge base accessible to the employees will facilitate the sharing of knowledge, dissemination of experience, know-how, and learning between the team members and other departments. More telling, the success of NPD and innovative capabilities require sharing information, and this is associated with effective and efficient strategic planning, program development and decision making, organizations' goals, and NPD performance, where all 
contribute to the firm's success, performance, and the sustainability of the competitive advantage.

The study aimed to fill the gap in the existing literature that addresses the success of NPD and the implementation of innovative capability through developing a comprehensive understanding of the critical role of shared knowledge and the organization's capabilities to the firm's sustainable competitive advantage. Organizations may benefit from this study by learning about the leading factors that contribute to NPD success and innovative capability regarding the contribution to the firm's success, performance, and sustainability.

The results of this study are critical to the field of innovation management because they provided a better understanding of the factors that impact and contribute to the success of NPD and innovative capability. The results are designated to help innovative organizations on factors that are ignored or have limited knowledge of their impact on the firm's performance. The exploration of this multi-site case study assists innovative organizations with strategic planning and decisions. Increasing awareness is one of the purposes of this multi-case study that of these factors, which may provide organizations with knowledge and foundation to consider in the strategic decision-making process and planning. The findings help academics and practitioners to better understand the role, impact, and the contribution of the integrated shared knowledge and the organizational capabilities to the firm's success, performance, and competitive sustainability.

The findings benefit both scholars and practitioners. The scholars can use the findings to develop new practices concerning NPD and innovative capability to support the firm's sustainable competitive advantage. The findings also contribute to managers and leaders of NPD and innovative capability, considering shared knowledge and the organization's capabilities as vital and essential to the organization's ability to develop new products and to promote innovative capability. All of this contributes to developing or improving a long-term sustainable strategic competitive advantage. The results of this multi-site case study are beneficial for innovative managers in making the appropriate strategic decisions concerning NPD and innovative capabilities that lead to attaining strategic goals.

The findings revealed interesting insights demonstrating how utilizing knowledge sharing and the organization's capabilities are linked and significantly related to NPD and innovative capability success. The results also indicated that shared knowledge enables the firm to improve and increase the innovative capabilities with new product competitive advantage, and the firm's performance. More importantly, shared knowledge and the organization's capabilities are deemed to be critical factors for the success of the NPD project and the implementation of the firm's innovative capability. This result implies a connection between knowledge sharing and the organization's capabilities, and the firm's success, performance, and sustainability.

This research study also addressed other factors shared by the participants, which need further study to determine their impact on the firm's NPD and innovative capabilities. Besides, the participants' shared insights also exposed some of the strategies adopted by the Jordanian's innovative organizations and other proactive actions that are used to cope with the 
challenges that their organizations faced on the local and global levels. These adaptive strategies are adopted to cope with the political changes in the surrounding areas, the turmoil in the market, the high level of competitiveness, the evolution of trends and consumers' demands, and the rapid developments of technology and communications. The main goal of the adopted strategies is to maintain their market share, address consumers' satisfaction, stay competitive, and to sustain their competitive advantage.

\section{Recommendations for Further Research}

This qualitative multi-case study contributes to the existing body of research knowledge. There are some possible extensions to this study. Some are a result of the limitations discussed above, and others are concerned with the depth and breadth of the shared perspectives of the participants. This study showed that the innovative organizations that are currently utilizing shared knowledge and the organization's capabilities have a better experience, performance, return, and expectations with the effectiveness of their NPD and innovative capability. Other types of sectors and industries, such as the service or hospitality industry, can be considered for future research, as could other countries where cultures, customs, and organizational structure, are entirely different. Future research can also consider other dimensions of NPD, such as the degree of innovativeness, cost, etc. Fourth, future research can assess NPD performance through other NPD performance measures such as product and market measures. Fifth, recommendation involves research techniques. Future researchers can deploy additional qualitative research techniques, such as focus groups, interviews, in-context observations, simulated environment observations, or document review. Quantitative research studies could examine the statistical significance among NPD, innovation capabilities, knowledge management, performance, key performance indicator (KPI), product development success, consumers' relations and feedback, marketing, and business model innovation. Finally, future research can also examine the effect of external factors on NPD success, performance, and speed. Recommendations for further research have emerged from the primary data, limitations in the study design, and delimitations. The researcher recommends further investigation, both qualitative and quantitative, about a broader range of participants in the innovation industry.

\section{Conclusion}

In a nutshell, the current multi-site case study concludes the research project on strategic management and innovation, practical NPD, and innovative capability. This study has begun as an effort to understand better the role of the shared knowledge and the organization's capabilities that impact NPD and the innovative capability regarding their contribution to the firm's success, performance, and sustainability. The researcher has designed this study to focus on the participant's perspectives and opinions in the field of innovation and strategic management, particularly NPD and innovative capability within organizations that currently utilize shared knowledge and the organization's capability.

The purpose of the research is to explore how shared knowledge and the organization's capabilities, affecting NPD and innovation capabilities, contribute to the firm's success and performance, and sustain the competitive advantage. The scholarly research has focused on 
the impact of the integrated shared knowledge and the organizational capabilities in the innovative Jordanian organizations. Participants confirmed that business is being affected by the integrated shared knowledge and organizational capabilities and contribute to the firm's success, performance, and sustainability. The focus of this research is to increase awareness and comprehension of the role of shared knowledge of the organization's capabilities that contribute to the success of the NPD and innovative capabilities. Also, the focus is to address the link between the integrated shared knowledge and the organizational capabilities to the firm's success, performance, and sustainability.

It is determined that there has been an improvement in the firm's performance and competitiveness when considering and implementing shared knowledge and the organization's capabilities through the firm's innovation activities and practices. Individuals who have had experience with NPD and innovative capability affirmed that their perception and experience of shared knowledge and the organization's capabilities had been positive and critical to NPD and innovative management. Data analysis, data results, findings, and recommendations from this study may be a desirable or suitable place to continue into the next phase of research for other researchers and this researcher alike.

\section{References}

Alvarez, H., \& Iske, P. (2015). Internal capabilities and external knowledge sourcing for product innovation in LMT SMEs. Journal of Innovation Management, 3, 55-70. Retrieved from http:/hdl.handle.net/10216/79104

Alvesson, M., \& Karreman, D. (2011). Qualitative research and theory development: mystery as method. Thousand Oaks, CA: Sage.

Anders, P. N. (2006). Understanding dynamic capabilities through knowledge management. Journal of Knowledge Management, 10, 59-71. https://doi.org/10.1108/13673270610679363

Anyan, F. (2013). The influence of power shifts in data collection and analysis stages: A focus on qualitative research interview. The Qualitative Report, 18(18), 1-9. http://tqr.nova.edu/

Awwad, A., \& Akroush, D. M. N. (2016). New product development performance success measures: exploratory research. EuroMed Journal of Business, 11, 2-29. https://doi.org/ 10.1108/emjb-12-2014-0043

Badrinarayanan, V., \& Arnett, D. (2014). Effective virtual new product development teams: An integrated framework. IEEE Engineering Management Review, 40, 80-90. https://doi.org/10.1109/emr.2012.6379403

Barclay, I., Dann, Z., \& Holroyd, P. (2000). Improving product development performance. New Product Development, 51-68. https://doi.org/10.1016/b978-0-7506-4998-8.50008-6

Bazeley, P., \& Jackson, K. (2013). Qualitative data analysis with NVivo. Thousand Oaks, CA: Sage. 
Brunswicker, S., \& Vanhaverbeke, W. (2014). Open innovation in small and medium-sized enterprises (SMEs): External knowledge sourcing strategies and internal organizational facilitators. Journal of Small Business Management, 53, 1241-1263. https://doi.org/10.1111/jsbm.12120

Cheung, T. M. (2015). Continuity and change in China's strategic innovation system. Issues and Studies, 51, 139-169. https://doi.org/10.1111/j.1460-2466.1994.tb00685.x

Cooper, R. G., \& Kleinschmidt, E. J. (2010). Success factors for new-product development. Wiley International Encyclopedia of Marketing. https://doi.org/10.1002/9781444316568.wiem05021

Dangol, R., \& Kos, A. (2014). Knightian uncertainty and risk. Journal of Strategy and Management, 7, 337-353. https://doi.org/10.1108/JSMA-02-2014-0010

Eisenhardt, K. M. (1989). Building theories from case study research. The Academy of Management Review, 14, 532. https://doi.org/10.2307/258557

Eisenhardt, K., \& Graebner, M. (2007). Theory building from cases: Opportunities and challenges. Academy of Management Journal, 50, 25-32. https://doi.org/10.5465/amj.2007.24160888

Ernst, H. (2002). Success factors of new product development: A review of the empirical literature. International Journal of Management Reviews, 4(1), 1-40. https://doi.org/10.1111/1468-2370.00075

Franzosi, R., Doyle, S., Mcclelland, L. E., Putnam Rankin, C., \& Vicari, S. (2013). Quantitative narrative analysis software options compared: PC-ACE and CAQDAS (ATLAS.ti, MAXqda, and NVivo). Quality and Quantity, 47, 3219-3247. https://doi.org/10.1007/s11135-012-9714-3

Hong, P., Doll, W. J., Nahm, A. Y., \& Li, X. (2004). Knowledge sharing in integrated product development. European Journal of Innovation Management, 7, 102-112. https://doi.org/10.1108/14601060410534393

Hussein, M. S. R., \& Mourad, M. (2014). The adoption of technological innovations in a B2B context: An empirical study on the higher education industry in Egypt. Journal of Business \& Industrial Marketing, 29, 525-545. https://doi.org/10.1108/jbim-07-2013-0155

Hyett, N., Kenny, A., \& Dickson-Swift, V. (2014). Methodology or method? A critical review of qualitative case study reports. International Journal of Qualitative Studies on Health and Well-being, 9. https://doi.org/10.3402/qhw.v9.23606.

Ismail, M., \& Yusof, Z. (2010). The impact of individual factors on knowledge sharing quality. Journal of Organizational Knowledge Management, 2010, 1-13. https://doi.org/10.5171/2010.327569

Jirwe, M. (2011). Analyzing qualitative data. Nurse Researcher, 18, 4-5. https://doi.org/10.7748/nr2011.04.18.3.4.c8456 
Kahn, K. B., Barczak, G., \& Moss, R. (2006). An exploratory investigation of NPD practices in nonprofit organizations. Journal of Product Innovation Management, 23, 512-527. https://doi.org/10.1111/j.1540-5885.2006. 00221.x

Kahn, K. B., Barczak, G., \& Moss, R. (2012). Identifying new product development best practices. Business Horizons, 55, 293-305. https://doi.org/10.1016/j.bushor.2012.01.006

Kalluri, V., \& Kodali, R. (2014). Analysis of new product development research: 1998-2009. Benchmarking: An International Journal, 21, 527-618. https://doi.org/10.1108/bij-06-2012-0040

Kang, S., \& Kim, S. (2010). The integrative framework on knowledge management and new product development. Asian Journal on Quality, 11, 157-164. https://doi.org/10.1108/15982681011075961

Lawson, B., \& Samson, D. (2001). Developing innovation capability in organizations: A dynamic capabilities approach. International Journal of Innovation Management, 5, 377-400. https://doi.org/10.1142/s1363919601000427

Li, X., Zheng, Y., \& Wang, C. L. (2016). Inter-firm collaboration in new product development in Chinese pharmaceutical companies. Asia Pacific Journal of Management, 33, 165-193. https://doi.org/10.1007/s10490-015-9451-y

Liker, J. K., \& Morgan, J. (2011). Lean Product development as a system: A case study of body and stamping development at Ford. Engineering Management Journal, 23, 16-28. https://doi.org/10.1080/10429247.2011.11431884

Lilleoere, A.-M., \& Hansen, E. H. (2011). Knowledge-sharing practices in pharmaceutical research and development- a case study. Knowledge and Process Management, 18(3), 121-132. https://doi.org/10.1002/kpm.379

Liu, Y., Wang, L., Yuan, C., \& Li, Y. (2012). Information communication, organizational capability, and new product development: An empirical study of Chinese firms. Journal of Technology Transfer, 37, 416-432. https://doi.org/10.1007/s10961-010-9188-1

Malewicki, D., \& Sivakumar, K. (2004). Patents and product development strategies: A model of antecedents and consequences of patent value. European Journal of Innovation Management, 7, 5-22. https://doi.org/10.1108/14601060410515600

Marshall, C., \& Rossman, G. B. (2016). Designing qualitative research (6th ed.). Thousand Oaks, CA: Sage.

Moustaghfir, K., \& Schiuma, G. (2013). Knowledge, learning, and innovation: Research and perspectives. Journal of Knowledge Management, 17, 495-510. https://doi.org/10.1108/JKM-04-2013-0141

Narkhede, B. E. (2017). Advance manufacturing strategy and firm performance. Benchmarking, an International Journal, 24, 62-101. https://doi.org/10.1108/bij-05-2015-0053 
Ngamkroeckjoti, C., Speece, M., \& Dimmitt, N. J. (2005). Environmental scanning in Thai food SMEs: The impact of technology strategy and technology turbulence. British Food Journal, 107(4), 285-305. https://doi.org/10.1108/00070700510596884

Noble, H., \& Smith, J. (2014). Qualitative data analysis: a practical example. Evidence-Based Nursing, 17, 2-3. doi:10.1136/eb-2013-101603

Patton, M. Q. (2015). Qualitative research \& evaluation methods: Integrating theory and practice (4th ed.). Thousand Oaks, CA: Sage.

Phillips, F. Y. (2016). The circle of innovation. Journal of Innovation Management, 4, 12-31. https://doi.org/10.1111/caim. v25.3

Roberts, C. (2010). The dissertation journey: A practical and comprehensive guide to planning, writing, and defending your dissertation (2nd ed.). Thousand Oaks, CA: Corwin.

Saunila, M., \& Ukko, J. (2013). Facilitating innovation capability through performance measurement. Management Research Review, 36, 991-1010. https://doi.org/10.1108/MRR-11-2011-0252

Schumpeter, J. Y. (2002). Schumpeter and the economic interpretation of history. Schumpeter and the Endogeneity of Technology. https://doi.org/10.4324/9780203465356.ch1

Seers, K. (2012). Qualitative data analysis. Evidence-Based Nursing, 15, 2. https://doi.org/10.1136/ebnurs.2011.100352

Singh, L., \& Bhangoo, K. S. (2014). The state, systems of innovation and economic growth: Comparative perspectives from India and South Korea. Seoul Journal of Economics, 27, 41-65. Retrieved from https://ssrn.com/abstract=2424561

Smithies, A. (n.d.). Schumpeter and Keynes. Schumpeter. https://doi.org/10.4159/harvard.9780674367340.c25

Stake, E. R. (1995). The art of case studies research. Thousand Oaks, CA: Sage.

Stake, R. (2006). Multiple case study analysis. [Kindle Ed.]. New York, NY: The Guilford Press.

Swanson, R. A., \& Holton, E. F., III. (Eds.) (2005). Research in organizations: Foundations and methods of inquiry. San Francisco, CA: Berrett-Koehler.

Teece, D. J., Pisano, G., \& Shuen, A. (1997). Dynamic capabilities and strategic management. Strategic Management Journal, 509-33. https://doi.org/10.1002/(sici)1097-0266(199708)18:7<509: aid-smj882>3.0.co;2-z

Teece, D. J., Pisano, G., \& Shuen, A. (2003). Dynamic capabilities and strategic management. Strategic Management Journal, 77-120. https://doi.org/10.1142/9789812796929_0004

Trier-Bieniek, A. (2012). Framing the telephone interview as a participant-centred tool for qualitative research: a methodological discussion. Qualitative Research, 12(6), 630-644. https://doi.org/10.1177/1468794112439005 


\section{Al Macrothink}

Journal of Management Research

ISSN 1941-899X 2021, Vol. 13, No. 1

Vinayak, K., \& Kodali, R. (2014). The relationship between NPD innovation and NPD performance: The moderating role of NPD best practices in the Indian manufacturing $\begin{array}{lllll}\text { industry. } & \text { Measuring } & \text { Business } & \text { Excellence, } & \text { 18, }\end{array}$ https://doi.org/10.1108/mbe-03-2013-0017

Xu, J., Houssin, R., Caillaud, E., \& Gardoni, M. (2010). The macro process of knowledge management for continuous innovation. Journal of Knowledge Management, 14, 573-591. https://doi.org/10.1108/13673271011059536

Yang, J., \& Yu, L. (2012). Electronic new product development - a conceptual framework. Industrial Management \& Data Systems, 102, 218-225.https://doi.org/ $10.1108 / 02635570210423262$

Yeşil, S., Koska, A., \& Büyükbeşe, T. (2013). Knowledge sharing process, innovation capability, and innovation performance: An empirical study. Procedia-Social and Behavioral Sciences, 217-225. https://doi.org/10.1016/j.sbspro.2013.04.025

Yin, K. R. (2014). Case study research: Design and methods (5th ed.). Thousand Oaks, CA: Sage.

Yin, K. R. (2015). Qualitative research from start to finish (2nd ed.). Thousand Oaks, CA: Sage.

Zhang, Y. (2012). Research on evaluation of enterprise core competence based on grey system theory. Advances in Information Technology and Industry Applications, 119-126. https://doi.org/10.1007/978-3-642-26001-8_16

Zhang, J., \& Zhu, M. (2015). Market orientation, product innovation and export performance: evidence from Chinese manufacturers. Journal of Strategic Marketing, 24, 377-397. https://doi.org/10.1080/0965254x.2015.1052538 